
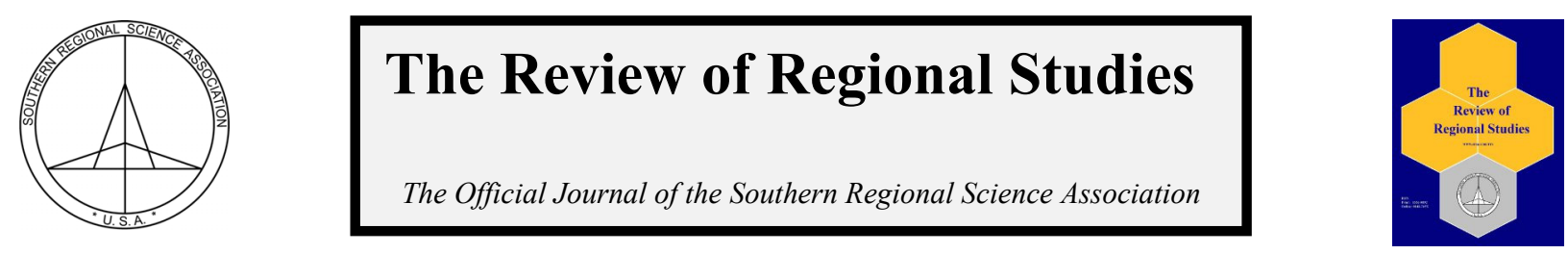

\title{
An Integrated Spatial Model of Population Change in South Carolina Counties
}

\author{
Willis Lewis, Jr, and Brooke Stanley \\ Department of Accounting, Finance, and Economics, Winthrop University, USA
}

\begin{abstract}
Existing studies of population change have grown to consider spatial dependence. The current literature highlights the importance of location when modeling population change. The evidence clearly suggests that population change in one area is dependent on population change in neighboring areas. What is missing in the existing literature is an analysis of which specific features in surrounding areas impact the local area. We employ a model using spatially lagged explanatory variables (SLX) to model population change in South Carolina. In addition to the normal impacts of the explanatory variables in a standard OLS regression, the SLX model measures the impact of the independent variables in contiguous areas. It also allows for separation of spillovers from rural counties versus those from urban counties. We find that the impact of neighboring counties is distinctly different for rural versus urban counties. Local urban population growth is influenced by neighboring counties, both urban and rural. However, local rural population growth is influenced only by neighboring rural counties. For rural counties, the share of retirees and recreational activities in surrounding rural counties are significant in explaining population change. For urban population growth, birth rates, income, and single female pregnancy rates in neighboring urban counties are significant. Retiree share and single female pregnancy rates in neighboring rural counties are also significant in explaining urban population change.
\end{abstract}

Keywords: population change, spatial econometrics, higher-order spatial regression models, regional differences

JEL Codes: O18, C21, C23, R10

\section{INTRODUCTION}

Understanding decentralization was the focus of previous economic research analyzing population change (Boarnet, 1994; Brown et al., 1997; Fuguitt and Brown, 1990). Prior to 1970, millions of Americans left rural areas to seek opportunities in urban areas. The rural revival that started during the $1970 \mathrm{~s}$, which brought people back to rural areas, prompted researchers to determine the causes of rural population growth to guide policies to stimulate growth in rural regions (Henry, Barkley, and Bao, 1997; English, Marcouiller, and Cordell, 2000). Later studies focused on population change attributed to specific features like highways (Baum-Snow, 2007; Chi, 2010) and natural amenities (English, Marcouiller, and Cordell, 2000; Beale and Johnson, 1998).

Boarnet (1994) and Chi (2010) used spatial econometric techniques to capture the effects of spatial dependence on population change. Boarnet used spatial econometrics to link nearby municipalities, demonstrating the impact of surrounding areas on local municipalities. However, his population model only included a spatial lag for employment in surrounding areas. Advances

Willis Lewis is Associate Professor of Economics and Brooke Stanley is Associate Professor of Finance at Winthrop University, Rock Hill, SC 29733. Corresponding Author: W. Lewis E-mail: lewisw@winthrop.edu

(C) Southern Regional Science Association 2016.

ISSN 1553-0892, 0048-749X (online)

www.srsa.org/rrs 
in spatial econometric software allowed Chi (2010) to correctly model population change. Chi's research concluded that population change in one area depends on population change in surrounding areas. However, his findings do not identify which factors in the surrounding counties are driving this impact. His work also did not address the heterogeneity and temporal issues raised by Chi and Ventura (2011).

Population change varies by region. The largest population gains since 1990 have been in the South and the West (Johnson, 2006). Most growth occurs in metropolitan areas with growing economies, then filters to suburban and nearby nonmetropolitan areas. Population decline generally occurs in areas with deteriorating economies - cities in the Rust Belt and remote rural areas dependent on farming and manufacturing. Unlike the Great Plains, total population grew in the rural South (Cromartie, 2014). However, there are regions within the South where population declined over the same time period. Examining these regional differences is one objective of this paper. Specifically, we estimate population change using the integrated framework suggested by Chi and Ventura (2011). Their framework controls for spatial autocorrelation, using variables across disciplines, and incorporates temporal trends in models of population change.

Our paper contributes to the literature on population change by applying these techniques to a southern state, South Carolina. This distinction is an important one because southern states tend to be more rural and have fewer employment opportunities. Also, commuting patterns cover several counties. Longer commuting distances may reduce an individual's propensity to migrate and may limit growth in rural areas. We also use spatially lagged independent variables to better measure local characteristics in this multicounty context, which advances the literature by giving insights into the mechanisms promoting regional population growth. Specifically, this study determines the impact of nearby rural counties compared to nearby urban counties on population growth in urban versus rural counties.

\section{LITERATURE}

\subsection{Factors Related to Population Change}

Early economic studies analyzed three emerging trends in population change - movement to the suburbs, movement to rural areas, and movement to warmer areas in the South and West (Carlino and Mills, 1987). These movements gained attention during the 1970s when manufacturing plants started moving to rural areas, which resulted in rural populations growing faster than urban populations. Johnson (1999) labeled this time period the "rural rebound." Prior to this period, rural population declined as residents moved to urban areas to take advantage of employment opportunities, recreational activities, and social interactions. The rebound offered hope for rural areas in terms of economic growth and rising incomes. However, there were concerns in urban areas as to whether cities were becoming less attractive, which might result in economic declines for those areas.

Rural population growth was less rapid during the 1980s but revived during the 1990s (Johnson, 1999). There was a slowdown toward the end of the 1990s but population growth returned after 2001 (Johnson, 2006). Johnson (2006) points out that some of the growth is because of a slight increase in births but most is attributed to an increase in migration from urban areas. The population growth came from retirees, blue-collar workers, lone-eagle professionals, and disenchanted city dwellers. People move to rural areas for a variety of different reasons, including a preference for less densely populated areas, to escape urban sprawl, local natural

(c) Southern Regional Science Association 2016. 
amenities, access to communication technology that allows individuals to work away from the office, lower housing costs, and manufacturing employment growth in those areas (Long, 1985; Fuguitt and Brown, 1990; Fuguitt and Beale, 1996; Brown et al., 1997; Johnson 2006).

Understanding the decentralization of population during the 1970s was the focus of many research studies. Boarnet (1994) found that population growth in northern New Jersey was higher in areas that were on highways, had lower poverty rates, had a lower frequency of violent crimes, had a newer housing stock, and had a larger Hispanic population. Carlino and Mills (1987) used county-level data for the entire United States to understand the determinants of population and employment growth. Their results suggest that weather, interstate highways, income, and employment are significant in explaining population change. All variables exhibit a significantly positive impact on population. Henry, Barkley, and Bao (1997) found that rural population grew as a result of nearby urban growth in South Carolina counties.

Later studies focused on population change caused by specific features like highway expansion (Baum-Snow, 2007; Chi, 2010) and natural amenities (English, Marcouiller, and Cordell, 2000; Beale and Johnson, 1998). Baum-Snow (2007) concluded that new highways decreased population growth in central cities in the United States from 1950-1990. Faster income growth also resulted in declining population for central cities. Natural amenities/tourism is another factor that promotes population growth. Rural counties dependent on tourism grew faster than other rural counties (English, Marcouiller, and Cordell, 2000; Beale and Johnson, 1998). Fuguitt and Beale (1996) also list amenities as a significant factor that influences migration. In general, rural areas with publicly controlled large lakes, forests, and mountain ranges attract tourists and migrants for the recreation and the quality of life provided by these resources (English, Marcouiller, and Cordell, 2000). The fact that home prices are rising near rural amenities supports the hypothesis that Americans are moving to rural areas for the local amenities and quality of life (English, Marcouiller, and Cordell, 2000).

Related studies of population change analyzed trends in migration patterns (Long 1985, Fuguitt and Beale, 1996; Cromartie and Nord, 1996). Beale and Johnson (1998) found that most of the population growth in the counties they examined was a result of net migration. Studies of migration trends have found that young, highly educated individuals in high income occupations are most likely to migrate (Fulton, Fuguitt, and Gibson, 1997). Fulton, Fuguitt, and Gibson (1997) studied changes in rural migration rates over three decades (the decline over the 1980s and the recoveries in the 1970s and 1990s) to identify demographic differences in migrants. They find that these individuals migrate between rural and urban areas to take advantage of economic opportunities. Fuguitt and Beale (1996) report similar findings, showing that decentralization has distinct patterns over time. Thus, a complete model of population change should incorporate temporal trends (Chi and Ventura, 2011).

Feasel and Rodini (2002) found that living in a rural area, the share of the population that is black, and low educational attainment are each related to a lower propensity to migrate. Similarly, Fulton, Fuguitt, and Gibson (1997) found little net-migration for blacks and those living in poverty over all time periods studied. The trend was for out-migration from rural areas for individuals aged 18-24 during the 1980s. The same held for blacks and those living in poverty. Then, in the 1990s, most migration was among those aged 30-59, as they were moving back to rural areas. In addition, the recovery of the 1990s was a result of increased in-migration, as well as retention of current residents. Increased commute times support retaining current residents (LMI SC, 2011).

(c) Southern Regional Science Association 2016. 
Mobility is another component of population change. In terms of the propensity to move, Brown et al. (1997) found that most people prefer to remain in their current area. In other words, rural residents prefer rural areas and urban residents prefer urban areas. Fulton, Fuguitt, and Gibson (1997) noted that rural areas are preferred by individuals that wanted to move. This supports the finding that more workers are becoming more willing to drive longer distances to work.

The extant literature has identified numerous variables related to mobility. Broadly speaking, they fall into two categories, the first of which is demographic characteristics of individuals. Mobility varies by gender (Keith and McWilliams, 1999). Race is also a factor, as whites (non-Hispanic) are less likely to move compared to most other races (U.S. Department of Commerce, 2001). Home ownership makes relocation less likely (U.S. Department of Commerce, 1997), as does length of residential tenure (DaVanzo, 1981). Being married (Long, 1988) reduces the likelihood of relocation. Kodrzycki (2001) found a positive relationship between education and the propensity to relocate, as those with a college education are more likely to move than those without. Age is a factor, with mobility peaking in the mid-twenties and declining thereafter (Long 1988). Feasel and Rodini (2002) found that those over age 65 or under age 18 are less likely to move.

The second category of variables relating to mobility is characteristics of the economic and legal environment to which individuals are exposed. Relative unemployment rates matter, as areas with higher (lower) rates of unemployment are more like to lose (gain) workers in search of employment (Greenwood, 1997). Similarly, areas with higher (lower) wages are more likely to gain (lose) workers (Rodgers and Rodgers, 2000). When interest rates rise, workers who own homes find it difficult to relocate since a new mortgage will have to be secured at a higher rate (Quigley, 2002). When home values change, workers who own homes may find relocation relatively more or less attractive (Donovan and Schnure, 2011). Variations in legal protections, such as those against mass layoffs and unfair dismissals, may also influence an area's ability to attract labor (Autor, Donahue and Schwab, 2004). Workers are more likely to move to areas with favorable climates, and more likely to leave those with less favorable weather (Kodrzycki, 2001; Greenwood, 1997).

Often only economic and demographic variables are commonly used to model mobility and population change. More recently, Chi (2010) incorporated additional variables to model population change. Specifically, highway expansion, different measures of transportation availability, land use, and natural amenities are used as explanatory variables to model population change. The addition of these types of factors results in the "complete model" described in Chi and Ventura (2011). He modeled population change in Wisconsin using variables based on previous research from several disciplines - demography, sociology, land-use planning, etc. This study is the first to model population change using a spatial error model with a spatially lagged dependent variable. The results suggest that spatial dependence is significant for rural and suburban areas but not urban areas. In addition, rural areas in the study grow in response to growth in surrounding areas. Conversely, suburban areas grow in response to growth in both the local area and surrounding areas.

\subsection{Spatial Dependence}

The impact of the surrounding areas in Chi (2010) refers to spatial dependence, which refers to the fact that an observation in one location depends on factors in that location and 
factors in surrounding locations. Boarnet (1994) used spatial econometric techniques, as described in Anselin (1988), to deal with spatial autocorrelation in cross-sectional data. Boarnet (1994) identified determinants of population and employment change in northern New Jersey from 1980 to 1988. Results from Boarnet (1994), which used spatial econometrics to link municipalities, improved our understanding of decentralization and the importance of commuting patterns. Chi (2010) used a spatial model that simultaneously controls for spatial dependence in the error term and a lagged dependent variable to determine the importance of highway expansion on population change.

When modeling spatial panel data, spatial dependence can be present in a spatially lagged dependent variable (spatial lag model), in the error term (spatial error model), in a combination of the two (general spatial model), or in spatially lagged independent variables (spatial Durbin model and the spatially lagged explanatory variables model).

The spatial error model (SEM) for panel data takes the following form:

(1) $\mathbf{y}_{\mathrm{it}}=\mathbf{X}_{\mathrm{it}} \boldsymbol{\beta}+\boldsymbol{\varepsilon}_{\mathrm{it}}, \boldsymbol{\varepsilon}_{\mathrm{it}}=\delta \mathbf{W} \boldsymbol{\varepsilon}_{\mathrm{it}}+\boldsymbol{e}_{\mathrm{it}}, \boldsymbol{e}_{\mathrm{it}} \sim N\left(0, \sigma^{2} I_{n}\right)$

where $y_{\text {it }}$ is an $n x 1$ vector of the dependent variable, $X_{i t}$ is the $n x k$ matrix of explanatory variables, $\beta$ is the $k$ parameters estimated, $\delta$ is the spatial error autocorrelation coefficient, $W$ is the $n \times n$ spatial weight matrix, and $\varepsilon$ is the normal error term for the regression model. Each observation is for spatial unit $i$ for each time period $t$.

The spatial autoregressive model (SAR) takes the form:

(2) $\mathbf{y}_{i t}=\rho \mathbf{W} \mathbf{y}_{i t}+\mathbf{X}_{i t} \boldsymbol{\beta}+\boldsymbol{\varepsilon}_{i t}, \boldsymbol{\varepsilon}_{i t} \sim N\left(0, \sigma^{2} I_{n}\right)$

In this model, $\rho$ is the spatial autoregressive parameter. However, it is possible that spatial dependence is present in the error term from the spatial autoregressive model. This results in the general spatial model (SAC), which takes the form:

(3) $\mathbf{y}_{\mathbf{i t}}=\rho \mathbf{W} \mathbf{y}_{\mathrm{it}}+\mathbf{X}_{\mathrm{it}} \boldsymbol{\beta}+\boldsymbol{\varepsilon}_{\mathrm{it}}, \boldsymbol{\varepsilon}_{\mathbf{i t}}=\delta \mathbf{W} \boldsymbol{\varepsilon}_{\mathrm{it}}+\boldsymbol{e}_{\mathrm{it}}, \boldsymbol{e} \sim N\left(0, \sigma^{2} I_{n}\right)$

The spatial Durbin model (SDM) considers the possibility of spatial dependence in the dependent variable as well as the independent variables. It takes the form:

(4) $\mathbf{y}_{\mathbf{i t}}=\rho \mathbf{W} \mathbf{y}_{\mathbf{i t}}+\mathbf{X}_{\mathbf{i t}} \boldsymbol{\beta}+\mathbf{W} \mathbf{X}_{\mathbf{i t}} \theta+\boldsymbol{\varepsilon}_{\mathbf{i t}}, \boldsymbol{\varepsilon}_{\mathbf{i t}} \sim N\left(0, \sigma^{2} I_{n}\right)$

Our goal is to separate the effect of neighboring rural counties from the effect of neighboring urban counties. This presents a problem with interpreting the impacts using the SDM. ${ }^{1}$ The spatially lagged explanatory variables model (SLX) is one of the models suggested by Lesage and Pace (2012) to avoid the pitfalls in higher order spatial models. The SLX takes the form:

(5) $\mathbf{y}_{\mathrm{it}}=\mathbf{X}_{\mathrm{it}} \boldsymbol{\beta}+\mathbf{W} \mathbf{X}_{\mathrm{it}} \boldsymbol{\theta}+\boldsymbol{\varepsilon}_{\mathrm{it}}$

Lesage and Pace (2012) present the following variant of the SLX that includes separate $\mathrm{W}$-matrices for different regions.

(6) $\mathbf{y}=\mathbf{X} \boldsymbol{\beta}+\mathbf{W}_{1} \mathbf{X} \boldsymbol{\theta}+\mathbf{W}_{\mathbf{2}} \mathbf{X} \gamma+\varepsilon$,

\footnotetext{
${ }^{1}$ Thanks to an anonymous reviewer for pointing out the pitfall.
}

(C) Southern Regional Science Association 2016. 
In their example, $W_{l}$ captures spillovers from neighboring counties within a state and $W_{2}$ captures spillovers from neighboring counties in a bordering state. We use this format to estimate population change.

We classify all 46 South Carolina counties as rural or urban using 2003 rural-urban continuum codes from the Economic Research Service (ERS). This classification produces 25 rural counties and 21 urban counties. We estimate separate models for rural counties and urban counties. $y_{\mathbf{r}}$ is the model for rural counties and $\boldsymbol{y}_{\mathbf{u}}$ is the model for urban counties.

(7) $y_{\mathrm{rt}}=X_{\mathrm{rt}} \beta_{\mathrm{r}}+W_{\mathrm{rr}} X_{\mathrm{rt}} \theta_{\mathrm{r}}+W_{\mathrm{ru}} X_{\mathrm{ut}} \gamma_{\mathrm{r}}+\varepsilon_{\mathrm{rt}}$

$y_{\mathrm{ut}}=X_{\mathrm{ut}} \beta_{\mathrm{u}}+W_{\mathrm{uu}} X_{\mathrm{ut}} \theta_{\mathrm{u}}+W_{\mathrm{ur}} X_{\mathrm{rt}} \gamma_{\mathrm{u}}+\varepsilon_{\mathrm{ut}}$

Now, the $n \times n$ matrix $W$ breaks down into the following: ${ }^{2}$

(8) $\mathbf{W}=\left(\begin{array}{ll}W_{r r} & W_{r u} \\ W_{u r} & W_{u u}\end{array}\right)$

For the model of rural population change, $W_{\text {rr }}$ and $W_{\text {ru }}$ are $25 \times 25$ row normalized contiguity matrices that capture the impact of counties surrounding rural counties. For rural county $i, W_{\text {rr }}$ captures the impact of surrounding rural counties and $W_{\text {ru }}$ captures the impact of surrounding urban counties. Similarly, $W_{\text {uu }}$ and $W_{\text {ur }}$ are $21 \times 21$ row normalized contiguity matrices that capture the impact of counties surrounding urban counties. For urban counties, $W_{\text {uu }}$ captures the impact of surrounding urban counties and $W_{\text {ur }}$ captures the impact of surrounding rural counties.

\section{DATA AND METHODS}

Unemployment rates were obtained from the Bureau of Labor and Statistics. County Business Patterns (U.S. Census Bureau) provided the firm and employment data. Regional Economic Information System (REIS) from the Bureau of Economic Analysis provided data on per capita income. Population, birth, and race data were obtained from the South Carolina Department of Health and Environmental Control. Annual data were collected for all counties for each year from 1998 to 2012. We estimate three panel regression models - all 46 counties over 14 time periods, 25 rural counties over 14 time periods, and 21 urban counties over 14 time periods.

The econometric specification adopted to model population takes the following form:

$$
\begin{gathered}
\text { PopChg }_{i t}=\beta_{0}+\beta_{1} \text { MfgShr } \\
+\beta_{i t}+\beta_{2} \text { IncomePC }_{i t}+\beta_{3} \text { Birth }_{i t}+\beta_{4} \text { RetireShr }_{i t}+\beta_{5} \text { SglPrg }_{i t} \\
+\beta_{6} \text { BlkSr }_{i t}+\beta_{7} \text { PovPct }_{i t}+\beta_{8} \text { Rec }_{i t}+\varepsilon_{i t}
\end{gathered}
$$

where PopChg it is the change in population in county $i$ in time period $t$. We describe in detail below the control variables included, as well as the expected sign of its effect on population growth.

Manufacturing share (MfgShrit) of total employment is included as previous research (Lewis, DiFurio, and Goode 2012) suggests that manufacturing was the dominant industry in most counties in South Carolina. In addition, McGranahan (1998) found areas that experienced population growth in the Great Plains also experienced growth in manufacturing employment.

\footnotetext{
${ }^{2}$ This study uses the queen contiguity matrix because of the irregular shape of many South Carolina counties as suggested by Owusu-Edusei and Chesson (2009).
}

(C) Southern Regional Science Association 2016. 
Manufacturing in rural counties tends to be in routine industries with relatively low wages. Metro counties tend to have more high-tech manufacturing with relatively high wage jobs. As a result, it is difficult to predict the sign of this coefficient a priori.

Per capita income (IncomePC $i t$ ) is used to measure a county's level of development. It is believed that greater incomes exemplify healthy, diversified economies that encourage population growth. We expect this variable to generate a positive coefficient.

We use births (Birthsit) to control for the normal growth in population resulting from births, since part of rural population growth can be attributed to higher birth rates. It is expected that the sign on this coefficient will be positive.

The retired population share (RetireShrit) is used to measure the share of retirees in the area. Individuals tend to retire to the South for the warmer climate. This should result in inmigration or a population increase. Conversely, retirement communities will provide limited employment opportunities for young adults who may leave the area, resulting in a population decrease. Hence, it is difficult to determine the sign of this coefficient.

The literature on Female head (FemHeadit) of household is mixed. Some find female heads are more likely to relocate to find employment opportunities (Feasel and Rodini, 2002). On the other hand, being the sole provider places an extra economic burden and may limit the ability to relocate. It is therefore difficult to determine the sign of this coefficient. The data do not allow for extraction of only single females. As a result, we use single female pregnancy rates $\left(\mathrm{SglPrg}_{i t}\right)$ as a proxy.

Black population share (BlkShrit) is included as another measure of local demographics. Feasel and Rodini (2002) find blacks are least likely of all races to migrate. It is expected that the sign on this coefficient will be negative.

Poverty rate (PovPctit) in the county is included to measure demographic differences. The legacy of poverty suggests that counties with large concentrations of poverty are more likely to have a high rate of unemployment and little job growth. As a result, these counties are more likely to have more out-migration and declining population as individuals leave in search of employment opportunities. The sign on this coefficient is expected to be negative.

The density of recreational activities (Recit) is a proxy for local amenities (Boarnet, 1994) and is also included to capture the social benefits of the county. Younger adults would most likely consider the availability of recreational activities before moving to an area. A greater density of recreational activities should attract individuals to an area, holding economic opportunities constant.

\section{RESULTS}

Table 1 reports the descriptive statistics for the explanatory variables used in the regression model. As expected, rural areas lag behind their metro counterparts. Population in metro counties grew by an average of over 3,100 individuals per year compared to fewer than 250 people in rural counties. The growth rates for most of the variables are of the same size and sign across county types except for birth rates and recreational activities. Rural counties had an average decline in births and urban areas had an average decline in recreational activities. Manufacturing employment share declined for both county types but the rate of decline for rural counties was twice that of urban counties. 
Table 1: Descriptive Statistics

\begin{tabular}{lccc}
\hline \hline Determinants & All Counties & Rural $(\mathrm{n}=25)$ & Urban $(\mathrm{n}=21)$ \\
\hline Population Change & $1,249.2$ & 248.1 & $3,126.4$ \\
Births & 0.195 & -0.011 & 0.003 \\
Manufacturing Share & 0.257 & -0.043 & -0.022 \\
Income & 0.008 & 0.034 & 0.033 \\
Recreational Activities & 0.053 & 0.017 & -0.005 \\
Share of Blacks & 0.031 & -0.003 & -0.001 \\
Poverty & 0.011 & 0.022 & 0.020 \\
Share of Retirees & 0.004 & 0.022 & 0.021 \\
Single Female Pregnancy & 0.021 & -0.025 & -0.033 \\
\hline \hline
\end{tabular}

\subsection{Regression Results}

Table 2 presents the results of the SLX models for all counties in South Carolina. Local, own-county impacts are shown in the top panel and the impacts of neighboring counties are shown in the lower panel. Similar to Chi (2010), we find that spatial dependence is present in population change in South Carolina. Unlike Chi (2010), the SLX model captures specific impacts of changes in each explanatory variable in neighboring counties as opposed to changes in population in neighboring counties. Looking at own-county impacts, population increases as there are decreases in local births, income, black population share, and poverty. Focusing on neighboring county impacts, more births in neighboring counties increase local population. Conversely, population declines with increases in income and single female pregnancy rates in neighboring counties. These results highlight the finding that population change in one county depends on changes in local factors in surrounding counties.

The landscape of South Carolina suggests a closer look (see Figure 1). There are 21 urban counties in South Carolina and most of them are along the I-85 and I-20 corridors. Most rural counties lie adjacent to urban counties. This feature highlights the significance of controlling for spatial dependence.

Figure 2 shows the county population change across South Carolina from 1998-2012. The dark clusters show regions of population decline and highlights the importance of location in population change. Population grew in the light areas which are the metro counties in South Carolina. The gradients show how population growth occurs in metro counties and spread to rural counties which signify spatial dependence. 
Table 2: SLX model estimates for all counties

\begin{tabular}{lc}
\hline \hline Variables & All Counties \\
\hline Local County & \\
Intercept & $6,313.51(15.36)^{* * *}$ \\
Births & $-58.97(-1.93)^{*}$ \\
Manufacturing Share & $37.01(1.32)$ \\
Income & $-3,924.69(-4.0)^{* * *}$ \\
Recreational Activities & $-9.33(-1.06)$ \\
Share of Blacks & $-200.53(-1.80)^{*}$ \\
Poverty & $-597.04(-1.64)^{*}$ \\
Share of Retirees & $-543.22(-0.81)$ \\
Single Female Pregnancy & $-153.46(-0.70)$ \\
Neighboring Counties & \\
Births & $2,935.45(2.38)^{* *}$ \\
Manufacturing Share & $1120.83(0.97)$ \\
Income & $-8,530.62(-2.02)^{* *}$ \\
Recreational Activities & $-189.94(-0.58)$ \\
Share of Blacks & $-2,112.77(-0.55)$ \\
Poverty & $-1,387.46(-1.44)$ \\
Share of Retirees & $1,876.52(0.62)$ \\
Single Female Pregnancy & $-0.93(-2.35)^{* *}$ \\
\hline$R^{2}$ & .8629 \\
\hline \hline Nit-ver & \\
\hline & \\
\hline & \\
\hline &
\end{tabular}

Notes: t-values in parentheses; Significance levels $*=0.1, * *=0.05, * * *=0.01$

(c) Southern Regional Science Association 2016. 
Figure 1: Rural/Metro Classification for SC Counties

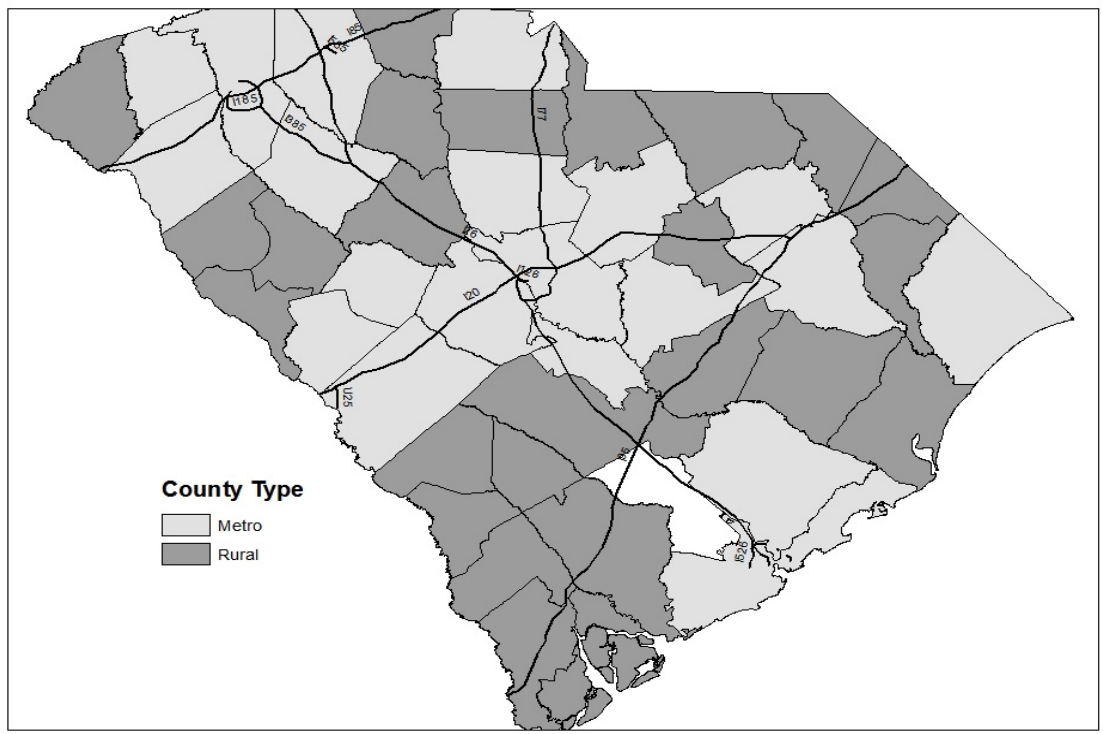

Figure 2: Population Change 1998-2012 for SC Counties

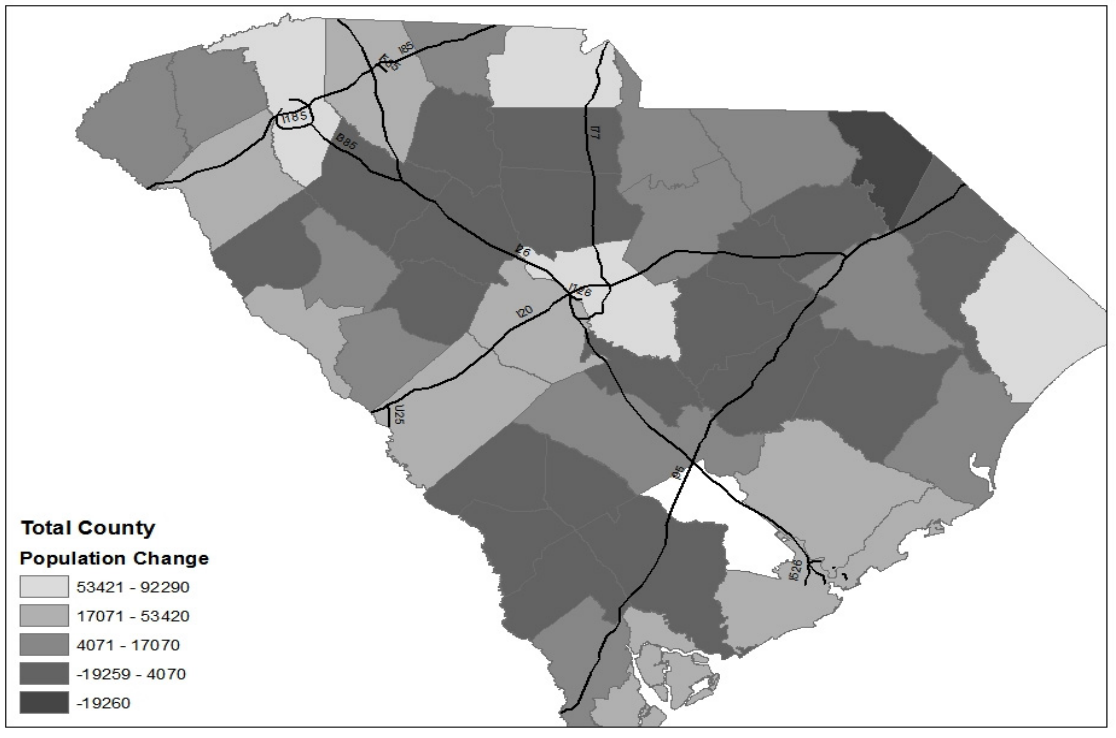

Note: Darker colors indicate declining population

The regression results for each county type are presented in Table 3. Local, own-county, impacts are shown in the top panel. The impacts from neighboring rural counties are presented in the middle panel and the impacts of neighboring urban counties are presented in the lower panel.

(c) Southern Regional Science Association 2016. 
Table 3: SLX model estimates by county type

\begin{tabular}{|c|c|c|}
\hline Variables & Rural & Urban \\
\hline \multicolumn{3}{|l|}{ Local County } \\
\hline Intercept & $-65.55(-0.17)$ & $3,826.24(3.17)^{* * *}$ \\
\hline Births & $-154.90(-0.56)$ & $1,146.95(0.93)$ \\
\hline Manufacturing Share & $-188.07(-0.71)$ & $890.99(0.86)$ \\
\hline Income & $-2,070.76(-2.41)^{* *}$ & $-9,947.22(-2.04)^{* *}$ \\
\hline Recreational Activities & $-65.99(-0.99)$ & $-441.35(-0.97)$ \\
\hline Share of Blacks & $-2,872.59(-2.83)^{* * *}$ & $-8,061.11(-2.45)^{* *}$ \\
\hline Poverty & $-164.08(-0.79)$ & $-608.98(-0.66)$ \\
\hline Share of Retirees & $-1,388.00(-1.81)^{*}$ & $-1,253.51(-0.47)$ \\
\hline Single Female Pregnancy & $0.24(1.25)$ & $0.85(3.14)^{* * *}$ \\
\hline \multicolumn{3}{|l|}{ Neighboring Urban Counties } \\
\hline Births & $-644.86(-1.28)$ & $-5,305.44(-2.20)^{* *}$ \\
\hline Manufacturing Share & $248.68(0.54)$ & $3121.76(1.35)$ \\
\hline Income & $-1,378.50(-0.76)$ & $-14,741.39(-2.14)^{* *}$ \\
\hline Recreational Activities & $79.89(0.37)$ & $-559.63(-0.63)$ \\
\hline Share of Blacks & $1,234.32(0.83)$ & $-8,471.55(-1.54)$ \\
\hline Poverty & $165.00(0.40)$ & $79.71(0.05)$ \\
\hline Share of Retirees & $-1,061.43(-1.01)$ & $5,721.49(1.16)$ \\
\hline Single Female Pregnancy & $-0.15(-1.15)$ & $-0.72(-1.78)^{*}$ \\
\hline \multicolumn{3}{|l|}{ Neighboring Rural Counties } \\
\hline Births & $292.18(0.59)$ & $2,418.11(1.46)$ \\
\hline Manufacturing Share & $231.96(0.51)$ & $677.22(0.40)$ \\
\hline Income & $-3.38(-0.00)$ & $4,395.54(0.80)$ \\
\hline Recreational Activities & $-208.06(-1.77)^{*}$ & $-453.35(-0.90)$ \\
\hline Share of Blacks & $2,322.20(1.35)$ & $6,599.15(1.04)$ \\
\hline Poverty & $-252.35(-0.63)$ & $132.65(0.12)$ \\
\hline Share of Retirees & $2,431.22(1.80)^{*}$ & $8,093.84(1.82)^{*}$ \\
\hline Single Female Pregnancy & $-0.062(-0.18)$ & $-2.76(-2.20)^{* *}$ \\
\hline$R^{2}$ & .8784 & .8717 \\
\hline
\end{tabular}

Notes: $t$-values in parentheses; Significance levels $*=0.1, * *=0.05, * * *=0.01$

For rural counties, income, black population share, and retiree share have significant impacts on local own-county population change. Population change is negatively impacted by all three variables in the local county. In urban counties, income and black population share also (c) Southern Regional Science Association 2016. 
negatively impact population change. However, retiree share has no impact whereas single female pregnancies have a positive impact on local population change in urban counties.

The impact of surrounding areas represents the indirect effects discussed in Chi (2010). The results also show that there is a significant impact from surrounding counties on local population change. Boarnet (1994) and Chi (2010) find significant rural/metro differences in population change. Hence, we run separate models for each county type given their findings and the differences in descriptive statistics between rural and metro counties presented above.

There are considerable differences for the effects of surrounding counties on population change in the local county. First, local urban population is influenced by changes in both surrounding urban and rural counties, whereas local rural population is influenced only by changes in surrounding rural counties. Specifically, local rural population declines as recreational activities increase, or as share of retirees decreases, in neighboring rural counties.

For urban counties, when neighboring urban counties experience decreases in birth rates, income, or single female pregnancy rates, then the local urban population increases. On the other hand, when neighboring rural counties experience an increase in retiree share or a decrease in single female pregnancy rates, then the local urban population increases.

Comparing the signs on coefficients of neighboring counties for local rural counties versus local urban counties, the signs are consistent for most variables. For neighboring urban counties, the coefficients differ in sign for recreational activities, black share, and retiree share. For neighboring rural counties, the coefficients differ in sign for only income and poverty.

\section{DISCUSSION}

This study provides a clearer understanding of population change in a predominantly rural southern state. However, there are limitations to this study. First, the findings of this study are limited to the county level. Caution must be used when generalizing the results to the city or census tract level. In addition, we are concerned with the impact of surrounding counties so we use all contiguous counties for the contiguity matrix which prevents exploration for the optimal weight matrix.

Understanding population change allows for better land-use planning and improved coordination of public resources across regions, and the results of the study support many hypotheses related to population growth and migration. Generally, population growth occurs in counties with robust economies and strong economic growth. More jobs provide better financial opportunities and attract individuals to those areas. However, the coefficient for income was negative and significant for rural and urban counties. This was unexpected as higher income is generally associated with greater economic development. However, it is possible that this variable is capturing the higher cost of living in a high-income area.

The results for the demographic variables included in the models warrant further discussion. First, single female pregnancy rate is used as a proxy for female heads of household. The coefficient for the variable is positive and significant only in the model for local urban counties. This is consistent with the findings of Feasel and Rodini (2002) and suggests that single female mothers are relocating to take advantage of economic and/or social opportunities. However, the positive sign could simply be because population growth is a result of more pregnancies. In addition, this suggests single mothers are not leaving their existing residences. The coefficients for both contiguous single female pregnancy rates are negative and significant.

(C) Southern Regional Science Association 2016. 
Stated differently, higher rates of single female pregnancy in neighboring counties reduce population in the local county. This finding supports the own-county results above that single mothers are not moving or relocating from their current residences. A report from the U.S. Department of Health and Human Services (2016) states that children of teenage mothers are more likely to drop out of high school, receive public assistance, and be poor as adults. Hence, assuming many of the single mothers in our study are teens, a large population of single mothers will result in a larger share of individuals that are least likely to move.

Next, South Carolina counties exhibit the "white flight" suggested by Boarnet (1994). The coefficient for own-county black population share is negative and significant across rural and urban counties. This is expected given that the black-belt passes through the state. The region is noted for having historically high rates of unemployment, poverty, and a large proportion of blacks. Till (1986) and Colclough (1988) find that counties with large black populations did not achieve as much job growth as other counties. Stifled economic growth in this region would result in out-migration of highly mobile individuals. This would result in a region with a large black population share, as Feasel and Rodini (2002) find that blacks have a lower propensity to move.

The negative sign for retiree share in the rural model could represent young adults leaving the area because of limited employment opportunities. As stated earlier, female head of household, black population share, the unemployment rate, child population share, and poverty rate are highly correlated for South Carolina counties. Considering these large correlations, the finding supports the theory of a growing population that has a lower propensity to move suggested by Feasel and Rodini (2002). The authors find that elderly individuals, teens, blacks, and those without a high school diploma have a lower propensity to move. The coefficient for the share of retirees in neighboring rural counties is positive and significant for both county types. This finding is consistent with English, Marcouiller, and Cordell (2000) and explains why the state is attracting retirees from other regions of the nation.

South Carolina is a southern rural state with a warm climate and many natural amenities like rivers, lakes, trails, and beaches for leisure activities. The positive effect for contiguous retiree share is appropriate given that these amenities span several counties to form a retirement region. We include a variable for recreational activities to capture the effect of local amenities. The coefficient is significant only for contiguous rural counties in the model for rural counties. The coefficient is negative and supports findings by English, Marcouiller, and Cordell (2000) that population growth is higher in rural areas with more local amenities.

The results of the SLX models highlight the existence of spatial dependence in population growth, and the results of separate models for rural and metro counties highlight important differences between the two county types. The results show that the impact from neighboring rural counties versus neighboring urban counties varies for each county type. While they are in close proximity, all spatially lagged explanatory variables for neighboring urban counties are insignificant in the rural population change model. Unlike the results of Henry, Barkley, and Bao (1997), we find that metro economies have no significant impact on rural population change. However, their study used an earlier time period for South Carolina, thus our results are not directly comparable.

Our findings suggest a regional approach for rural economic development in South Carolina. As Chi (2010) suggests, a regional approach is better for growth and development in 
rural areas. Workers in the state are willing to commute to take advantage of employment opportunities. About 85 percent of all counties have more workers commuting out of the county (LMI SC, 2011) for work. Only two out of thirty rural counties have a net inflow of commuting workers. Hence, job growth in the commuting zone will benefit residence of several counties.

The results also show the importance of controlling for spatial dependence when modeling population change. Using the SLX models, we illustrate the importance of the independent variables in surrounding areas in population growth. We also show that those effects vary across county types. Our findings suggest tourism may provide development opportunities for rural areas in South Carolina. Efforts to promote the state as a retirement destination may benefit rural areas across the state. This would be helpful to a predominantly rural state where rural economies still lag metro economies.

Many rural counties in South Carolina are adjacent to metro counties. Future research needs to closely look at the relationship between metro growth and rural population. Also, more investigation is needed to understand the relation between population change and per capita income in the county. Answering these questions will improve the current understanding of population growth.

\section{REFERENCES}

Anselin, Luc. (1988) Spatial Econometrics: Methods and Models. Kluwer Academic Publishers: Dordrecht.

Autor, David, John Donahue, and Stewart Schwab. (2004) "The Employment Consequences of Wrongful Discharge Laws: Large, Small or None at All?," American Economic Review Papers and Proceedings, 94, 440-446.

Baum-Snow, Nathaniel. (2007) "Did Highways Cause Suburbanization?," Quarterly Journal of Economics, 122, 775-805.

Beale, Calvin L. and Kenneth M. Johnson. (1998) "The Identification of Recreational Counties in Nonmetropolitan Areas of the United States," Population Research Policy Review, 17, $37-53$.

Boarnet, Marlon G. (1994) "An Empirical Model of Intrametropolitan Population and Employment Growth," Papers in Regional Science, 73, 135-153.

Brown, David L., Glenn V. Fuguitt, Tim B. Heaton, Saba Waseem. (1997) “Continuities in Size of Place Preferences in the United States, 1972-1992,” Rural Sociology, 62, 408-428.

Carlino, Gerald A. and Edwin S. Mills. (1987) “The Determinants of County Growth,” Journal of Regional Science, 27, 39-54.

Chi, Guangqing. (2010) "The Impacts of Highway Expansion on Population Change: An Integrated Spatial Approach," Rural Sociology, 75, 58-89.

Chi, Guangqing, and Stephen J. Ventura. (2011) “An Integrated Framework of Population Change: Influential Factors, Spatial Dynamics, and Temporal Variation," Growth and Change, 42, 549-70.

(c) Southern Regional Science Association 2016. 
Cromartie, John. (2014) "Population and Migration," USDA Economic Research Service. Last accessed March 2016 at: http://www.ers.usda.gov/topics/rural-economypopulation/population-migration.aspx.

Cromartie, John B. and Mark Nord. (1996) "Migration and Economic Restructuring in Nonmetro America, 1989-1994," ERS Staff Paper 9615, Rural Economic Division, Economic Research Service, U.S. Department of Agriculture.

Donovan, Colleen and Calvin Schnure. (2011) "Locked in the House: Do Underwater Mortgages Reduce Labor Market Mobility?,” Working Paper SSRN 1856073.

English, Donald K., David W. Marcouiller, and H.K. Cordell. (2000) "Tourism Dependence in Rural America: Estimates and Effects," Society and Natural Resources, 13, 185-202.

Feasel, Edward M. and Mark L. Rodini. (2002) "Understanding Unemployment across California Counties," Economic Inquiry, 40, 12-30.

Fuguitt, Glenn V. and Calvin L. Beale. (1996) "Recent Trends in Nonmetropolitan Migration: Toward a New Turnaround," Growth and Change, 27, 156-74.

Fuguitt, Glenn V. and David L. Brown. (1990) "Residential Preferences and Population Redistribution: 1972-1988," Demography, 27, 589-600.

Fulton, John A., Glenn V. Fuguitt, and Richard M. Gibson. (1997) "Recent Changes in Metropolitan-Nonmetropolitan Migration Streams," Rural Sociology, 62, 363-384.

Greenwood, Michael. (1997) "Internal Migration in Developed Countries," in Mark R. Rosenzweig and Oded Stark (eds), Handbook of Population and Family Economics. Elsevier Science: New York City, pp. 647-720.

Henry, Mark S., David L. Barkley, and Shuming Bao. (1997) "The Hinterland's Stake in Metropolitan Growth: Evidence from Selected Southern Regions," Journal of Regional Science, 37, 479-501.

Johnson, Kenneth M. (1999) "The Rural Rebound," Population Reference Bureau Reports on America, 1, 1-21.

(2006) "Rural America Undergoing a Diversity of Demographic Change," Population Reference Bureau. Last accessed March 2016 at: http://www.prb.org/Publications/Articles/2006/RuralAmericaUndergoingaDiversityofDemograph icChange.aspx

Keith, Kristen and Abagail McWilliams. (1999) "The Returns to Mobility and Job Search by Gender," Industrial and Labor Relations Review, 52, 460-477.

Kodrzycki, Yolanda. (2001) "Migration of Recent College Graduates," New England Economic Review, 1, 13-34.

LeSage, James and R. Kelley Pace. (2011) "Pitfalls in Higher Order Model Extensions of Basic Spatial Regression Methodology," Review of Regional Studies, 41, 13-26.

Lewis, Willis, Ferdinand DiFurio, and Timothy Goode. (2012) "Testing for the Presence of Spatial Dependence in Manufacturing Employment in South Carolina Counties," Southern Business and Economic Journal, 34, 41-53.

(C) Southern Regional Science Association 2016. 
Long, John F. (1985) "Migration and the Phases of Population Redistribution," Journal of Development Economics, 17, 43-45.

Long, Larry. (1988) Migration and Residential Mobility in the United States. Russell Sage Foundation: New York.

McGranahan, David. (1998) "Can Manufacturing Reverse Rural Great Plains Depopulation?," Rural Development Perspectives, 13, 35-45.

Office of Adolescent Health of the U.S. Department of Health and Human Services. (2016) Teen Pregnancy and Childbearing. Last accessed March 2016 at: http://www.hhs.gov/ash/oah/adolescent-health-topics/reproductive-health/teenpregnancy/\#_ftn2

Owusu-Edusei, Jr., Kwame and Harrell Chesson. (2009) "Using Spatial Regression Methods to Examine the Association Between County-Level Racial/Ethnic Composition and Reported Cases of Chlamydia and Gonorrhea: An Illustration With Data From the State of Texas," Sexually Transmitted Diseases, 10, 657-664.

Quigley, John M. (2002) "Homeowner Mobility and Mortgage Rates: New Evidence from the 1990s" Real Estate Economics, 30, 345-364.

Rodgers, Joan and John Rodgers. (2000) "The Effect of Geographic Mobility on Male LaborForce Participants in the United States," Journal of Labor Research, 21, 117-132.

South Carolina Department of Employment and Workforce. (2013) South Carolina 2011 Commuting Patterns Analysis. Last accessed March 2016 at: http://lmi.dew.sc.gov/lmi\%20site/Documents/CommutingPDFs/SC2011CommutingPatte rns.pdf.

U.S. Department of Commerce. (1997) Current Population Reports, Geographical Mobility: March 1995-March 1996, report P20-497.

. (2001) Current Population Reports, Geographical Mobility: Population Characteristics, March 1999-March 2000, report P20-538.

(c) Southern Regional Science Association 2016. 